\title{
Project Driven Orders Managing Practices in Polish Construction Industry
}

\author{
Katarzyna Marek-Kolodziej ${ }^{1}$, Iwona Lapunka ${ }^{1}$, Iwona Pisz ${ }^{2, *}$ \\ ${ }^{1}$ Faculty of Production Engineering and Logistics, Department of Project Management, Opole University of Technology, \\ Opole, 45-370, Poland \\ ${ }^{2}$ Faculty of Economics, Department of Logistics and Marketing, Opole University, Opole, 45-058, Poland \\ *Corresponding Author: ipisz@uni.opole.pl
}

Copyright (C) 2014 Horizon Research Publishing All rights reserved.

\begin{abstract}
Contemporary enterprises, focused on external business environment, define their strategic targets, with regard to the context of market and customer requirements. Their internal organization form should aim towards transformations, driven by global economic, political and social processes. This further involves rejecting of existing stereotypes, distribution of tasks and functions performance, as well as a possibility to adapt in response to environment variations, being well exemplified by project driven organizations. Management of individual single orders in enterprises with functional structures can be treated as "project driven orders" management. The orders may have manufacturing or service type. From this reason it is necessity to implement project driven approach for efficient performance in these enterprises. The paper presents the current state of information, determiners of orders management transformation towards project driven approach and the preliminary research results, obtained from analysis of project driven orders management efficiency in chosen Polish construction enterprises from Opole Province. The research aimed at encompassing a context focused on competencies and knowledge development within the group of enterprises under research, resulting from a permanent need of transformation within companies, managing project driven orders, from traditional organization types to dynamic project driven organizations, with features of knowledge-based organizations.
\end{abstract}

Keywords Project Driven Order, Effectiveness of Project Management, Manager Competencies, Knowledge Management, Organizational Project Management Maturity, SMEs

\section{Introduction}

During several recent years, transformation of economic orientation from a production orientation into a market one, involved a necessity for the entrepreneurs to search for new ways of development and maintaining on the market of goods and services. Increasing uncertainty, frequently resulting from fast occurrence of changes, resulted in a necessity to create and implement new approaches to management in companies. One of the methods of attaining it is to introduce solutions based on paradigms of project management. In practice of enterprises with traditional organization structures, management of individual, single orders, including manufacturing or service orders, involves characteristics of a project with a necessity of implementing project driven approach to achieve efficient performance.

A project is defined as a temporary endeavor undertaken to create a unique product or service [18]. Most companies, particularly small and medium size enterprises have to manage various projects, which share a pool of constrained resources, taking into account various objectives at the same time. Not only one but several, even dozens or hundreds of projects are typically going on at the same time within an enterprise [13].

Methods and techniques of project management may be applied if efficient implementing of an enterprise strategy is to be achieved. Project management constitutes an appropriate tool for quality improvement programmes implementing, as it involves holistic approach to organization changes [25].

The aim of the paper is to present preliminary research results, within a selected group of enterprises, divided into small and medium size enterprises (SMEs) and large enterprises in Opole Province, representing construction industry. Human resources management, a very significant issue in project management was under particular focus. In accordance with the statement that "people do projects", a constant increase of human factor importance has been noticed in the implementation of projects, because shaping of the main project processes depends widely on the knowledge and competencies of employees, and first of all on their organization behaviour and approach. The level of specialist, technical, social and personal competencies of project team members and the project manager, who ought to represent an appropriate level of management competencies, 
influence the success of a project. An efficient project management, which constitutes an element of key features of an enterprise, may become a source of its competitive advantage.

\section{Research Background}

Increasing the frequency of orders with customers is an important objective for many enterprises project driven management. The orders are vital part of these types of enterprises and have large impact on enterprises. The good experiences and customer satisfaction have impact on customer loyalty and good customer references. Therefore the project planning play a significant role in enterprises, especially in small and medium-sized enterprises. An order ordered by a customer can be treated as an unique project, i.e. project driven order. This type of order takes place only on receipt of customers' orders.

A customer order planning treated as unique project project driven order - play a significant role in enterprises, especially in SMEs. According to the definition of micro, small and medium-sized enterprises prepared by European Commission the micro enterprise is an enterprise with fewer than 10 employees, and turnover of less than $€ 2$ million, small enterprise is an enterprise with fewer than 50 employees, and turnover of less than $€ 10$ million. The medium sized enterprise is an enterprise with fewer than 250 employees, and turnover of less than $€ 50$ million [4]. These type of enterprises play a very important role in the economy as economic and social development [1], [2], [5], [6], [10], [19]. The SMEs account $99,8 \%$ of all companies in the European Union, generate $56 \%$ of GDP and employ $67 \%$ of private sector workers [4], [20]. According to paper [23] projects account on average for one third of the turnover of SMEs. Additionally, the paper shows that the projects in small and size enterprises account for almost one fifth of the economy.

Projects become more and more important in management of all kinds of enterprises: in enterprises, units of public and local-government administrations, nonprofit organizations, consortia, with their presence noticed in almost any human activity (jobs, business, science, culture, sport, administration), which undoubtedly brings demand for professional knowledge and management competencies within this scope. In Poland, the number of orders, considered to be project driven order, permanently increases. This refers mainly to such fields as public works, construction industry, aviation and defence industry, shipbuilding industry, IT programming etc.

Planning and realization of projects always have a certain level of uncertainty. This is due to the fact, that projects are often innovative and unique and it is difficult to predict the direction of realization in uncertain situations. The uncertainty is the result of not having full access to information and characteristics of a project type, and can be defined as probability that the objective function will not reach its planned target value [7]. The inside and outside conditions of project management are full of uncertainty. It is result of changing customer requirements, resource utilization, personnel mobility, economical turbulence, etc. Under such conditions the enterprises have to manage several different projects. In that context such imprecise data as duration time of activities, cost of each activity, utilization rate of resources, and so on, have to be taken into account, while responding to the growing needs to solve uncertainty in project management [16].

Methods of project management constitute a way of incorporating project execution in a real life, and they constitute an instrument for reaching basic aims, such as: time and date of execution, cost and quality of effect [8], [9]. Project success, undoubtedly constitutes a part of all the factors and of correct communication, being crucial in the process of project management (Figure 1).

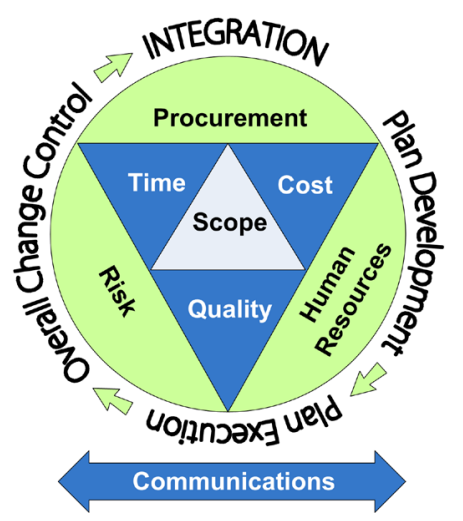

Figure 1. Activities and areas focused on successful project management (iron triangle)

Exceeding time frame of a project, insufficient resources, incorrect calculation of budget, unclear targets, or conflicts within a team constitute the most frequent problems to deal with by project managers and project team members. The latest Standish Group research, published in The Chaos Manifesto: Think Big, Act Small indicate, that only 39\% of projects end up successfully, whereas $43 \%$ meet serious difficulties, and $18 \%$ of projects result in losses only [22].

Project iron triangle (Figure 1) - triple constraint in management - is also subject to the impact of economic directions evolutions. New definition of success in project execution, focuses mainly on quality and customer satisfaction, slightly reducing the meaning of core aspects, such as time, cost and scope (Figure 2). Development of soft success factors is emphasized: an appropriate set of project teams' competencies, high intellectual capital, accurate communication, and project knowledge management.

Contemporary conditions of dynamic, competitive market cause, that most of enterprises in construction industry have to take specific orders, resulting almost as frequently as taking them, in serious problems during their execution. Most of orders obtained by companies constitute individual and single works and services processes, which require detailed analysis, planning and development of appropriate 
management methods. These are therefore frequently considered projects, pursuant to the classic PMI definition, formulated in PMBOK Guide [18].

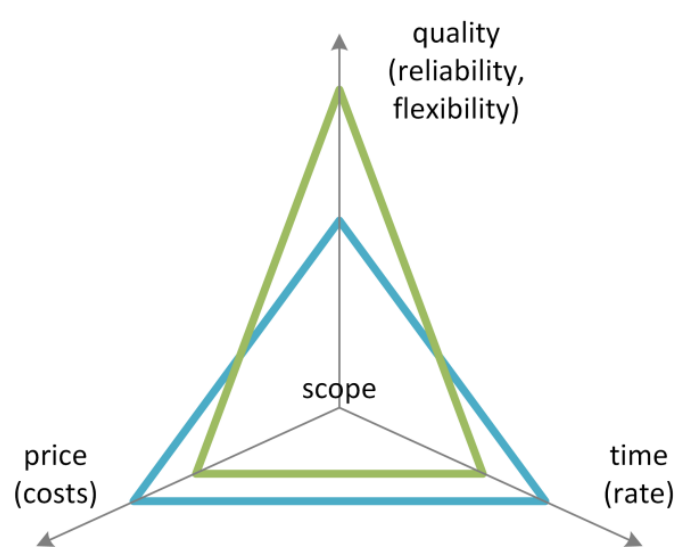

Figure 2. Constraints triangle modification in relation to variations of market preferences

In case of manufacturer's, this involves quite frequently, a necessity to develop a completely new approach, based on the application of typical project management methods with dominating operational and repeated activities. Discreet manufacturing, considered as manufacturing of outstanding units of goods, on the customer's order and pursuant to the customer's specification of requirements, is more and more frequently associated with the term "project driven order" [16]. The term can also be used for determining the so called construction projects. In principle, this is a key element of construction investment execution process - the main task of an investment project, executed in close connection with its aims and constraints. Nevertheless, as there are no general conditions in force in Poland, regarding construction works agreements, such as for example the international FIDIC conditions (contract conditions for engineering and construction works), or the German VOB (conditions for construction works), every contract is concluded on the basis of individual contract stipulations, and involves other risks: commercial, financial, technical, legal. For this reason, it may be considered as an individual set of activities executed under sub-contracting basis, as a project driven order.

Change of the method of business running, the pervasive phenomenon of outsourcing (of services, processes, sub-projects and also some of an enterprise functions), distinguishing of tasks of a routine character within system, as well as the tasks of unique character, provides crucial premises for increasing the importance of project driven orders in the basic activities of enterprises. Process approach and project approach are important, from the point of view of maintaining a position a given enterprise on its market.

\section{Research Problem}

A group of enterprises with traditional structure, which perform project driven orders are particularly at risk of competitive advantage loss, since project management is based on the implementing of wide knowledge, experience, tools, methods and techniques in planning activities, in order to obtain or exceed the needs and expectations of clients. This in particular, is related with the necessity to adjust many parameters, such as time, cost, needs, expectations of a project client, and the aims of the project.

A question which occurs, is whether the project teams organized for the project, working temporarily outside their company organization structures are able to meet the requirements? Whether managers of project driven orders have an appropriate set of competencies: knowledge from a given scope (I know what), abilities (procedures - I know how, and I can do it), or attitudes (I want and I am ready to use my knowledge)? Whether construction industry enterprises in Poland use (and if they do - to what extent), solutions characteristic for project organizations, and whether the activities improve competitive advantage of enterprises? Finally, what are the constraints met by construction industry enterprises, in respect of project knowledge management development in the organization, and what opportunities of economic growth for enterprises represent solutions proper for project type organizations dedicated for the industry under analysis?

The main purpose of the research is to determine level of project maturity in Polish enterprises with majority of routine operating activities, within traditional organization forms (permanent system of functional and hierarchic relations), which perform project driven orders and indicate directions of orders/contracts management improvement, from the perspective of project organization features. It is finally assumed that the analyses and conclusions made, will result in an increase of the project maturity level in enterprises under research, through recommendation of innovative solutions in respect of projects execution scope, contracts, and project driven orders.

The context of the research, focused on competencies and knowledge development within the group of enterprises under research, resulting from a permanent need of transformation within companies managing project driven orders, from traditional organization types to dynamic project driven organizations, with features of knowledge-based organizations. The processes of generative learning lead to obtaining new solutions, facilitate search for new approaches to problems, and are therefore crucial for development of project maturity in modern enterprises.

\section{Representative Research}

Empirical research included construction industry companies. The enterprises perform project driven orders (SMEs sector) or construction projects (large enterprise), and apply elements of project approach in economic activities. The type of the activities is characterised by the project uniqueness, its complexity, time specification and a certain technical, organization and economic risk. They are 
performed by teams of highly qualified contractors from various disciplines (interdisciplinary), and require application of special methods of preparation and execution. Competencies of projects managers should be focused certainly on the project success, i.e. reaching an assumed superior purpose within a planned time, within the cost planned, according to project quality parameters assumed.

The research included 25 enterprises from Opole Province, from the SMEs construction industry sector, including 5 micro companies, 12 small enterprises and 8 medium enterprises. To counterweigh the selection, the research results have been compared with practices of large companies, which perform construction projects on the order of an employer, as a crucial element of construction investment execution process. The research has been done with project management staff, employed in one of Opole companies, providing various services, including thermal industrial insulation, assembly of specialist dust removal installations and assembly of interior drywall finishing. The research included 16 project managers performing investment ventures nationally and abroad.

Due to specific character of the research, it applied uncontrolled observation techniques and free interview. It provided a better method of presenting the process of project driven orders, defining the manager's function from the point of view of key success factors, and indicate shortcomings in the selection of project teams. It moreover facilitated watching the shaping of social organization and technological systems level development, and methods of compounding, as well as communicating useful project management knowledge, within the group of companies under research.

\subsection{Characteristics of the Project Driven Orders Management in SMEs}

Introduction of a project management approach in an enterprise, is particularly important for enterprises within the group of small and medium size enterprises. SMEs sector constitutes a part of economy which develops very dynamically. Companies which are included in the group of small and medium size enterprises are able to react to variations in the market fastest - which involves the fact that they may easily adapt to it. Large economic entities are not so flexible. These conditions allow small and medium size enterprises act and develop actively in economic niche areas and in low potential markets. Measures taken by companies from the SMEs sector contribute therefore to an increase of the whole economy efficiency. Nevertheless, enterprises of this kind are sensitive to variations in the market, they are at risk of turbulences resulting from economic crisis.

Research on implementing of project management into practice of enterprises, in particular the small and medium size enterprises becomes particularly important. Research into the status of project management of SMEs sector has been conducted in an insignificant extent [1], [11], [14], [15], [16], [23], [24]. Based on the study of literature we can say that project management in small and medium-sized enterprises is different than project management in the large enterprises. In industrial practice the SMEs use simply planning and control systems of projects. The procedure of project management is usually not standarized. Not all SMEs use sophisticated methods dedicated for example project planning like PERT method. These types of enterprises seldom implement projects methodology like PMI, PRINCE2. Additional, small and medium-sized enterprises do not tent to use tools, computers software dedicated for project management like Microsoft Project. In small enterprises we cannot find a project office. The projects are managed by other primary roles not by project manager [23], [24].

Analysis of results obtained by the authors of the article indicates unequivocally, that most of the enterprises under research (i.e. about $80 \%$ ), within the group of SMEs, have not implemented any approach dedicated for project driven orders management. Projects undertaken by entrepreneurs are characterized by relatively short execution times, in case of micro-companies (up to 3 months). Projects execution periods, in case of a small and medium size enterprise are significantly longer, they are on average $3-6$, or $6-9$ months long.

Projects management is a field where the so called project management competences models or project managers competencies models can be noticed to become very popular [26]. Organizations responsible for their elaboration and development include usually professional associations such as: Project Management Association (IPMA Competency Baseline), Project Management Institute (Project Manager Competency Development Framework), Engineering Construction Industry Training Board (National Occupational Standards for Project Management), Australian Institute for Project Management (Professional Competency Standards for Project Management).

From the point of view of world standards, the models established so far indicate scope of complex and detailed guidelines which define elements and levels of project competencies, needed and required from organizations and from employees who perform specific roles, functions and positions.

Project management practice in small and medium size enterprises is however totally different from standards established. Research conducted so far by the authors indicates that modern SMEs usually do not undertake projects based on analysis of competencies such as: knowledge, abilities, approaches and behaviour of employees obtaining outstanding results.

Project manager's function in SMEs sector is rather not clear. The so called project manager, frequently is a group manager or an owner of a company in micro and small enterprises, and in medium size enterprises it is usually not more than a site manager. Too frequently, the enterprise owner is directly engaged in the process of project management (this shortcoming has been stated in 13 out of the enterprises under research). A company owner, or a 
president is very close to operations issues, with personal insight into every project driven order task, which is feasible, due to the enterprise range. The owner, as the main decision-maker, has a strong need for "manual" control in risk situations, acting initially as a diligent observer, then quickly transforming into project manager, superseding the manager in charge from his position. An enterprise owner engaged in the process of project driven order, is usually too much concerned about his own business - apart from external customer who pays for an order, the owner cares for satisfying his needs during the execution of a project.

Specifics of small and medium size enterprises certainly lead to a situation, that many phenomena in projects are typical, not only for the project, but for the enterprise. In most of enterprises under research, all project driven orders are performed within the same working processes (technology), but the same negative situations occur in all construction ventures.

A project team is unchanged. In small and medium size enterprises frequently the same staffs perform similar tasks. The issue of project team selection, not to mention the key competencies of its members, usually does not even exist. Not many of them use appropriate tools and methods of project management. Simultaneously, certain formal and informal methods of communication remain unchanged as we deal with the same team.

Lack of proper competencies (knowledge, abilities and attitudes) of project team members, including project managers of projects performed by SMEs, cause significant consequences in reaching (or not) of the project purpose, within a specific time, at planned cost and of required quality. Level of project maturity of individual companies is very different, and project awareness of construction team members (project teams) is also varied, but is definitely on a low level.

Transformation of project initiative into material results, creating a value for organization within enterprises under research from the construction branch in the SMEs sector is chaotic, in principle significantly tangential from project base programmes assumed at the beginning, without implemented methods of project management methodologies, and it usually reminds rather ad hoc activities than a systematic collection of methods forming a cohesive approach to project management.

Exceeding a directive deadline for project execution appears in each of the enterprises under research. Financial penalties imposed by the contractors constitute a consequence of exceeding the directive deadline in medium size enterprise. Micro and small enterprises usually negotiate extension of execution time with contractors which lower their reliability viewed by customers, loss of next orders of a given customer. In relation to cost management the research indicates mainly weak points of practice in project approach of the enterprises under research. Most of enterprises under research do not apply sufficient project calculation, which results measurably in exceeding the planned budget level.

Entrepreneurs have indicated, that they do not use knowledge or experience of staff working at previous project driven orders (almost $80 \%$ ) in estimating the time and cost of individual tasks in a project. No other formal methods, or tools for project execution time or cost estimating are used by them ( $67 \%$ of micro and small enterprises).

\subsection{Characteristics of the Project Driven Orders Management in Large Enterprise}

The research included 16 project contract managers (considered as project managers), responsible for planning, organization and control of project execution in one of construction enterprises providing their services in Opole Province. Most of employees selected include persons employed by the enterprise as a result of incorporating economic transformations. The information is important in determining project management knowledge of the persons under research. The level of their knowledge, experience and skills, influence largely the success of projects performed. In large enterprises, a project manager is certainly a crucial person, with clearly defined function and tasks. This was the case in the enterprise under research.

Worth noting is the fact that majority of contracts performed by the company are of external character - over $93 \%$ of projects, with $68 \%$ of projects with international range. Slightly over $31 \%$ of projects are projects performed nationally. Projects managers most frequently deal with projects with 1-6 months execution time, and their budget is about several million PLN.

More than half of the projects finish within the time set, and they do not exceed the budget scheduled. It may therefore be assumed, that projects managers meet their duties correctly as far as programming and project execution are concerned.

Research data indicate, that the company have got a correct staff recruitment system, as the position of a project manager is occupied by a person with high qualifications, usually with college degree and professional high school education- this refers to over $62 \%$ of employees within this group of employment.

Nevertheless, in spite of the fact that the staffs represent high level of field knowledge regarding the subject of project execution, it is noticed that the managers do not possess important knowledge in respect of key project management areas. Over $87 \%$ of staff do not know or do not apply the basic methods and tools of project planning such as CPM, PERT or Gantt scheduling. There may be several reasons for obtaining a negative response. First of all, project managers schedule and execute tasks pursuant to inner enterprise procedures, included in their Quality Management Programme, which does not include the terms. Another important reason of the situation may be the fact, that the project managers under the research are mostly employees of the company who joined it after incorporating economic transformations. Project managers participating in the transformations have knowledge directed more to its practical use than structural association, which may result 
from the fact that their mother company implemented a different system of staff training [12].

Over $81 \%$ of persons under research, use MS Excel in their job in project planning, organization and execution. There are also some cases of using MS Project by the persons. This means, that the employees reveal a slight will of implementing IT tools, which support the project management process. They are however attached mainly to the traditional methods elaborated by themselves.

A majority of project managers in a large enterprise have confirmed that they collect and archive project execution knowledge (such response has been provided by about $94 \%$ of persons questioned). The most frequent archiving activities involve simple elaboration of electronic memos and their storage in databases established for their own use. Persons under the research confirmed regular and frequent use of such practical knowledge. This is usually related with initial stage of project execution. Worth noting is the fact, that in spite of a declaration regarding collection of knowledge related with the project execution, it is difficult to notice any activity in the process of its processing or sharing.

As far as the required characteristics and skills of a project manager are concerned, most of the responses under research cover what has been described in the literature on the subject - that a project manager should be characterised by the following: (1) ability to cooperate with people, (2) efficient global negotiating with persons directly involved in a project, (3) possibility of efficient team building.

For a deeper analysis of the research, the manager of highest enterprise management level has been additionally interviewed. The board has been concerned about the preliminary research results, in particular in respect of project manager's knowledge on the methods and tools of project management. It is further planned to repeat the research regarding managers responsible for the execution of strategic projects, who had been trained on this issue in the past. This shall provide verification of the theses stated regarding the causes of insufficient level of knowledge on the crucial project management areas.

\section{Comparative Analysis}

Knowledge in the activity of organizations, including execution of project driven orders is crucial for obtaining permanent competitive advantage of enterprises [19]. It integrates processes regarding creativity, innovation, contacts with the client, application of best practices, learning and development of abilities. It also covers the aspects of building a culture based on knowledge. In projects management the issue obtains a new character, because it is transferred to a field of dynamic, time limited, temporary and team performed ventures.

Efficient project management requires knowledge and skills from the project manager. Managerial competencies include ten main knowledge areas necessary to be known by a project manager well prepared for his function. These knowledge areas are [18]: (1) Project Integration
Management, (2) Project Scope Management, (3) Project Time Management, (4) Project Cost Management, (5) Project Quality Management, (6) Project Human Resource Management, (7) Project Communications Management, (8) Project Risk Management, (9) Project Procurement Management, and (10) Project Stakeholders Management (added in the 5th edition of PMBOK Guide).

In an attempt to reach standards dedicated to project organizations, it should be noticed, that enterprises in construction industry have enormous possibilities of learning from projects. Frequently however, the measures taken by them do not confirm the assumptions. The end of a project is associated with having exhausted the possibility of learning, and the effects of learning under one project are not communicated to others, and become forgotten. This brings enterprises a high cost related with lost opportunities of project management techniques and methods improvement. Modern enterprises can and should learn from projects, by using the knowledge resources collected and providing employees opportunities for drawing conclusions from activities performed and their effects. A condition for use and implementing of the knowledge is to collect it, and to make it available to all employees.

Knowledge transfer between individual levels of project knowledge management within an organization, features relationships in the sequence: creating-collectionproviding-use of intellectual capital. Knowledge transfer between the global (international, over organizational) and the local levels (within organization, in a project or individual) is based on: (1) providing of collections, standards, publications, (2) transfer of experience and elements of knowledge from business to science.

Within the local levels of project knowledge management, the knowledge of project team members and their competencies facilitate generating innovative solutions and providing knowledge. At the level of a project, knowledge may be obtained from an organization which offers proper knowledge management conditions (in particular in respect of its generating, capitalizing and providing), as well as from individual level - from a project team.

The correlation identified, between the level of enterprises project knowledge and efficiency of projects management, contributed to initiating a comparative analysis of the enterprises under research (SMEs and a large company), in relation to selected areas of knowledge, indicated by the enterprises under analysis, as particularly important for the construction industry. It can be noticed, that a large company has got a more extensive project knowledge (Figure 3), which significantly influences a higher set of its competencies in project management. Worth noting is the fact of focusing the enterprise under research on knowledge of natural and legal environment of the project under execution. An excellent knowledge of regulations under construction law and care for proper policy, regarding Corporate Social Responsibility (CSR), creates a proper image of the organization. 


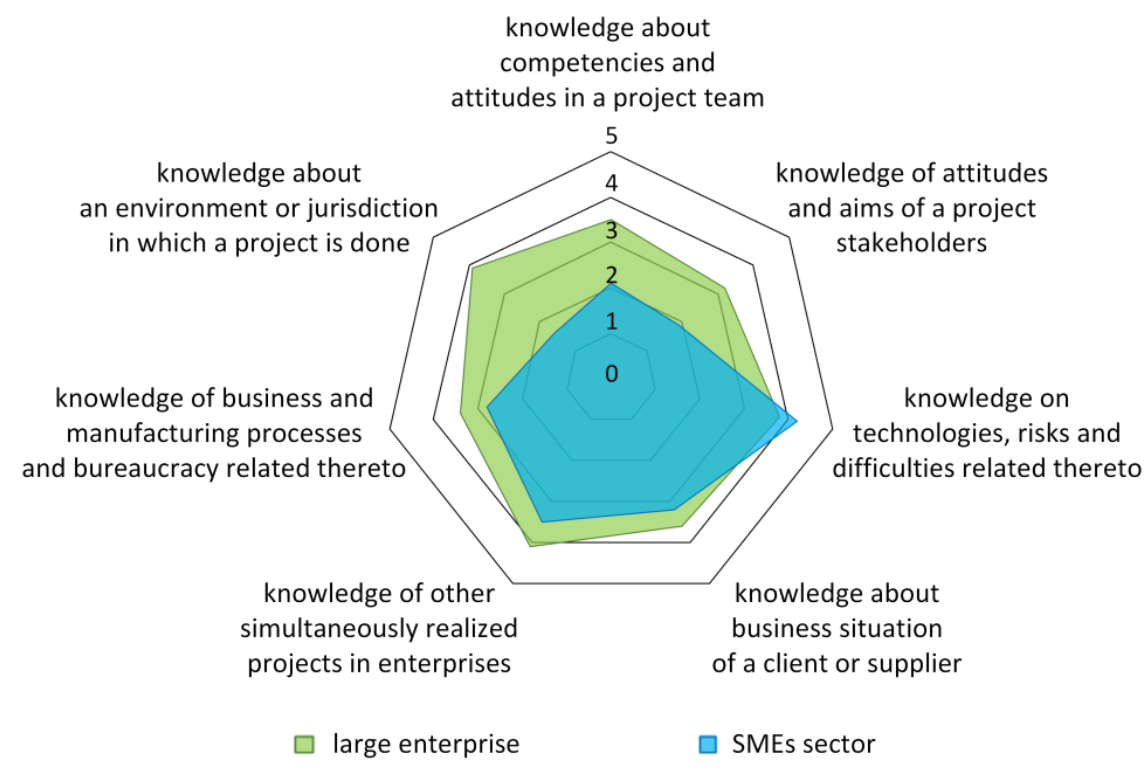

Figure 3. Level of knowledge in projects, on the basis of knowledge areas under research

Much better, in case of a large enterprise is also knowledge about competencies and attitudes in a project team. Care for human factor increases significantly the chances of a project success. Traditional staff recruitment transforms into obtaining intellectual capital. The most important factor however, is not the size of the enterprise, but its culture, where the employees constitute the company's most important assets, and the process of learning transforms into education leading to an increase of entrepreneurship.

Knowledge of attitudes and aims of a project stakeholders is at a higher demand in a large enterprise than within a SMEs group. The fact results from the specifics of construction projects execution, projects which are concluded on the basis of individual contractual stipulations, which estimate commercial, financial, technical and legal risks, including those related with the parties.

An interesting result has been obtained for knowledge on technologies, risks and difficulties related thereto. It is the only area, in which the SMEs group reveal a higher level of its knowledge. This is somehow realistically substantiated, since innovative technologies applied in a large enterprise and the level of their complexity level, undoubtedly dominates among other construction industry enterprises under research. This gives basis for the claimed lack of knowledge on all technical aspects included in goods and services of high technological intensity level. A group of SMEs usually offer their customers solutions and technologies which are known and reliable, which do not cause to much difficulty in execution of project driven orders.

\section{Conclusions}

The level of project maturity in individual enterprises varies significantly. At the same time the project awareness of the project teams under analysis (construction teams) varies, but it is certainly at a relatively low level, in case of the whole SMEs group, with a slightly higher level in case of construction project managers group employed in a large enterprise.

Main conclusion of the observations and analyses above is the fact, that in particular, the small and medium size enterprises need competent project managers, who will be able to manage efficiently, and manage execution: introduce organization variations and new technologies, implement strategic development projects, hand over construction objects on time, pursuant to budget and quality requirements.

A large enterprise has got such managers, in spite of certain shortcomings revealed during research, in respect of their knowledge on project management methods and tools. To summarize quality research results obtained from entities of SME sector, it should be emphasized that there is a certainly a low level of project driven orders execution solutions implementing, proper for intelligent organizations. It is compliant with the hypothesis assumed, that the key problem in projects execution is an improper management of project knowledge, revealed by low efficiency of its use, and mainly a weak ability of organizations to accumulate project knowledge and loss of organization memory. The phenomena result in an insignificant efficiency of projects, low quality of results, dissatisfaction of project employers and ineffective management of resources designed for their execution. Weak level of organizations learning and use of project experience leads to an unwillingness towards execution of innovative projects, and as a result to a loss of chances - not only from the point of view of business activity but also of the social and macroeconomic ones.

To improve the situation the following recommendations were indicated, in individual interviews with management members of SMEs sector and managers of construction contracts in large enterprises: (1) documenting of the 
knowledge obtained in projects, at best on regular basis, (2) generating employment and cooperation conditions which support knowledge exchange, (3) maintaining of organization knowledge map, (4) search for knowledge existing within an organization, before "wheel starts being invented" again. The instructions listed, directly influence project management, which in its essence is related with knowledge processing. Project team members, who have specialist knowledge - work together under a project, to supply new products and services on time, according to budget and specified quality criteria. From this point of view, it is important for a project manager to manage knowledge of its own team and interested parties - he/she should integrate it as much as possible to facilitate successful execution of a project. Project team members, also manage their knowledge - individually and in a team - using the possessed knowledge and attaining new knowledge, handing it over to others and creating together new knowledge within an organization. Application of knowledge management methods in projects execution is therefore significantly substantiated in order to guarantee success in ventures executed.

Knowledge based economy opens new challenge for enterprises, in efficient and effective development of organization learning processes. The research conducted indicates, that the level of progress of business entities with permanent structures in adjustment to current economic challenges is still quite low.

An organization may gain advantage by systematic collection of knowledge and experience related with projects execution. Knowledge management processes execution allow identification of the so called best practices in project management and determining of the most efficient mechanisms of problem solving. Moreover, learning at projects facilitates continuous development and improvement of processes and projects' products, and constitutes an opportunity for further improvement of project management methods and techniques. Within a long time perspective, project knowledge management allows an organization development of project competencies, which allow it obtaining or maintaining competitive advantage, improving at the same time the organization project maturity.

\section{REFERENCES}

[1] Acedo F., Florin J., An entrepreneurial cognition perspective on the internationalization of SMEs, Journal of International Entrepreneurship, Vol.4, No.1, 2006, 49-67.

[2] Audretsch D., Research issues relating to structure, competition, and performance of small technology-based firms, Small Business Economics, Vol.16, No.1, 2001, 37-51.

[3] Dziekoński K., Project management in small and medium-sized enterprises, Economics and Management, No.4, 2010, 97-104 (in Polish).
[4] European Commission, Putting small businesses first: Europe is good for SMEs, SMEs are good for Europe, European Commission Publications Office, Luxembourg, 2008.

[5] Floyd D., McManus J., The role of SMEs in improving the competitive position of the European Union, European Business Review, Vol.17, Issue 2, 2005, 144-150.

[6] Hallberg K., Small and medium scale enterprises: a framework for intervention, Small Enterprise Unit, Private Sector Development Department, The World Bank, Washington, DC, USA, 1999.

[7] Jaafari A., Management of risk, uncertainties and opportunities on projects: time for a fundamental shift, International Journal of Project Management, Vol.19, 2001, 89-101.

[8] Leach L.P., Lean project management: eight principles for success, Advanced Projects, Boise, Idaho, 2005.

[9] Lock D., Project management, 9th edition, Gower Publishing Ltd, Hampshire, Great Britain, 2009.

[10] Low D., Chapman R., Inter-relationships between innovation and market orientation of SMEs, Management Research News, Vol.30, No.12, 2007, 878-891.

[11] Łapuńka I., Biniasz D., The measurement of project managers competencies in construction enterprises. Entrepreneurship and Management. Vol.12, Part 2, 2013, 101-111 (in Polish).

[12] Marek-Kołodziej K., Skomudek W., Evaluation of knowledge level of project managers in using modern management method, Enterprise Management, 2014, in print, (in Polish).

[13] Martinsuo M., Lehtonen P., Role of single-project management in achieving portfolio management efficiency, International Journal of Project Management, Vol.25, 2007, 56-65.

[14] Murphy A., Ledwith A., Project management tools and techniques in high-technology SMEs, Management Research News, Vol.30, No.2, 2007, 153-166.

[15] Owens J.D., Why do some UK SMEs still find the implementation of a new product development process problematic? An explanatory investigation, Management Decision, Vol.45, No.2, 2006, 235-251.

[16] Pisz I., Banaszak Z., Project management subject to imprecise activity network and cost estimation constraints, Applied Computer Science, Vol.6, No.1, 2010, 7-28.

[17] Pisz I., Łapuńka I., Project management in small and medium-sized enterprises - the results of researches, Materials and Logistics, No.7, 2012, 16-22 (in Polish).

[18] PMI Standards Committee, A guide to the project management body of knowledge, 5th edition, PMI, Newtown Square, PA, USA, 2013.

[19] Salvato C., Lassini U., Wiklund J., Dynamics of external growth in SMEs: Process of model acquisition capabilities emergence, Schmalebach Business Review, Vol.59, No.3, 2007, 282-305.

[20] SBA Fact Sheet 2012, Enterprise and industry - Poland, European Commission, Brussels, 2012.

[21] Sense A., Antoni M., Exploring the politics of project 
learning, International Journal of Project Management, No.21, 2003, 487-494.

[22] The Chaos Manifesto 2013: Think big, act small, The Standish Group International, Boston, MA, USA 2013, Online available from http://www.standishgroup.com

[23] Turney J.R., Ledwith A., Kelly J.F., Project management in small to medium-sized enterprises. A comparison between firms by size and industry, International Journal of Managing Projects in Business, Vol.2, No.2, 2009, 282-296.
[24] Turney J.R., Ledwith A., Kelly J., Project management in small to medium-sized enterprises: matching process to the nature of the firm. International Journal of Project Management, Vol.28, 2010, 744-755.

[25] Von Dran G., Kappelman L., Prybutok V., Empowerment and the management of an organizational transformation project, Project Management Journal, Vol.27, No.1, 1996, 12-17.

[26] Wyrozębski P., Competencies models in project management, E-mentor, No.2, 2009, 55 (in Polish). 